\begin{tabular}{|l|l|l|l|l|l|}
\hline MUNIBE Antropologia-Arkeologia & $n^{\circ} 69$ & $75-91$ & DONOSTIA & 2018 & ISSN 1132-2217 • eISSN 2172-4555 \\
\hline
\end{tabular}

\title{
Poblamiento prehistórico de la península ibérica: dinámica demográfica versus frecuencias del C14
}

\author{
Prehistoric settlement of the Iberian Peninsula: \\ demographic dynamics versus C14 frequencies
}

\author{
PALABRAS CLAVES: Carbono 14; Paleolítico; Mesolítico; Neolítico; Calibración. \\ GAKO-HITZAK: Paleolitoa, Mesolitoa, Neolitoa, Kalibrazioa, Karbono-14 \\ KEY WORDS: Paleolithic, mesolithic, neolithic, calibration, 14C
}

Alfonso ALDAY RUIZ(1) y Adriana SOTO SEBASTIÁN(1)

\section{RESUMEN}

El trabajo reúne y analiza 1.395 dataciones C14 de la prehistoria ibérica, del lapso cronológico 13000-5000 BP. A partir de ellas se plantea si las mismas sirven para evaluar correctamente el poblamiento tanto a nivel ibérico como entre las regiones en las que se divide el territorio. Para su evaluación se sigue el procedimiento de suma de probabilidades una vez calibradas cada uno de los resultados. Como variación a los sistemas tradicionales se incorpora una rutina matemática que evita las duplicaciones de contextos repetidamente datados (con valores solapados). En la lectura de los resultados obtenidos (regional y globalmente) se tienen en cuentan los factores derivados de la curva de calibración, los sesgos tafonómicos y de investigación, así como eventos climáticos. En consecuencia, se observa que la compilación de fechas puede producir efectos ilusorios, ya advertidos críticamente por Bayliss, de tal manera que debe sopesarse con cuidado su valor como proxy de la demografía prehistórica. Las ausencias en tramos temporales y geográficos remiten a problemas de invisibilidad de registros arqueológico, y las alteraciones en las frecuencias tiene que mucho que ver con los cambios en las estrategias humanas.

\section{LABURPENA}

Lan honetan, 13000 -5000 BP tarteko iberiar penintsulako 1395 datu erradiokarbonikoak biltzen eta aztertzen ditugu. Datu erradiokarboniko bakoitzak kalibratu ondoren probabilitate gehieketa egiten dugu, ariketa matematiko berria inplementatuz kontextu arkeologiko berean errepikatzen diren datazioak saihesteko. Gure helburua datu erradiokarboak proxy demografiko moduan erabiltzearen balioa aztertzea da, hau da, bildutako datazioek iberiar penintsulako populazioaren eboluzioa isladatzen dute? Lortutako emaitzen interpretazioan faktore ezberdinak hartu ditugu kontuan: kalibrazio kurbaren irregularitateak, sesgo tafonomikoak eta akademikoak, eta klimaren eboluzioa. Lanaren ondoria Bayliss autorearen interpretazioan lerrotzen da: datu erradiokarbonikoen gehieketak ez du zuzenki populazioaren eboluzioa isladatzen. Gehieketaren emaitza faktore ezberdinengatik influentziatua dago, bi faktore nabarmenduz hutsune kronologiko eta geografikoak azaltzeko: arazo tafonomikoak eta ikuspen gutxiko erregistro arkeologikoaren eragina, baita historiaurreko gizarteen estrategia ekonomiko eta sozialena ere.

\section{ABSTRACT}

In this work we analyse 1,395 14C dates from the Iberian prehistory, belonging to the 13000-5000 BP chronological span. The only selection criterion considers their accuracy: a standard deviation of less than a century was required. It is the largest compilation published for this geographical area. Each date has been calibrated using OxCal program and IntCal13 calibration curve before the construction of the summed calibrated date probability distributions (SCDPD). We have followed the habitual methodology for the SCDPD, incorporating a mathematical routine into our process that avoids duplications of overlapping data from contexts repeatedly dated. At the same time, for a detailed evaluation, the exercise is also performed individually for different regions: Cantabrian region, Ebro basin, Central plateau, Catalonia, Valencia, Andalusia and Portugal. The aim of this work is to evaluate in which way this kind of compilations can be interpreted as demographic proxy, in this case as the Iberian population dynamics during the final Paleolithic and the first half of the Holocene.

In this sense, we think that for interpreting the SCDPD it is firstly necessary to evaluate different factors that could distort the final distribution: factors related to the calibration curve itself, to taphonomic and research biases, or to the methodology employed. We also observe the individualised behaviors between the series of samples of long and short life that, contrary to the assumption, do not show striking dissonances. On the other hand, the participation of some very specific archaeological contexts, such as shell middens, can originate false demographic processes derived from their high archaeological visibility and their easy dating. For this reason, we justify the exclusion of certain archaeological sites, like the multiple megalithic burials for the end of our sequence, in these kind of exercises. They could create an overrepresentation.

On the other hand, our interpretation is linked to the detailed knowledge of the archaeological contexts. We think that the understanding of a SCDPD only makes sense in the permanent dialogue between the radiocarbon data and the known archaeological record (and even the absent one). It is necessary to know the cultural (pre)historical development involved; the functionality of the sites; the archaeological research programs... The opposite is to make interpretations without a critical reading of the archaeological record. In this sense, as an example, the

\footnotetext{
(1) a.aldayruiz@ehu.eus Departamento de Geografía, Prehistoria y Arqueología. Facultad de Letras. Tomas y Valiente s/n. 01006
} 
sharp drop in the date probability frequency after the start of the Neolithic, which in the logic of these kind of studies would attribute to a loss of population, could be related with changes in the strategies adopted by those societies.

In conclusion, we think that the compilation of ${ }^{14} \mathrm{C}$ dates can produce illusory effects, already warned critically by $\mathrm{A}$. Bayliss, that they must be corrected by the archaeologist - the data by themselves do not do archeology-. The SCDPD cannot be taken as a proxy of prehistoric demography. The absence of data in temporary sections and geographic areas could refer to invisibility problems of the archaeological record, and the modifications in the probability frequencies are related with different human decisions about the exploitation of the territories, the number and characters of the deposits generated, or the inherent problems of the dating method and the exploitation of the results. The demographic patterns are hidden under these problems.

\section{INTRODUCCIÓN}

Reunimos 1.395 dataciones de 317 yacimientos de la península ibérica, para el lapso cronológico 130005000 BP (15500-5500 cal BP), para, a partir de este corpus y conocido el registro arqueológico, proponer una lectura crítica de los resultados en relación al poblamiento y la demografía.

Los trabajos de compilación de fechas de C14 es una deriva de la aplicación de los big data a la ciencia prehistórica. La calidad de los trabajos de campo, de sus publicaciones y del desarrollo de software de fácil aplicación para la calibración y su tratamiento estadístico, son la base de las investigaciones. Pero no es suficiente con reunir datos y aplicar procedimientos accesibles, también es necesario comprender el significado de los valores que se han reunido. En este sentido es fundamental conocer cómo se construye un registro arqueológico, cómo se conserva, cómo se rescata y cómo se analiza. Un contexto arqueológico es el resultado de diversas actividades humanas desigualmente fosilizadas: significa que lo reunido en una base cronológica tiene diferentes orígenes al responder a estrategias humanas varias donde no todos sus elementos originales se han conservado. Es decir, las compilaciones vinculan yacimientos heterogéneos solo por estar fechados.

También sabemos que no conocemos todos los elementos del pasado prehistórico de un área y tiempo determinado: contrariamente se presupone una importante pérdida informativa y, entre los sitios considerados varios tienen problemas para avalar su integridad. Por tanto, un sesgo tafonómico afectará a los repositorios, que reunirán de lo conservado aquello que ha podido ser datado. Además, aunque las técnicas de excavación se han depurado ofreciendo una óptima recuperación de la información arqueológica, no es menos cierto que las políticas de investigación, los recursos técnicos, los económicos, y la disponibilidad de los arqueólogos seleccionan lo que se rescata, analiza y publica. Por tanto, nos enfrentamos también a un sesgo de investigación.

Desde nuestra perspectiva pensamos que los resultados de la aplicación de las técnicas de cronología absoluta no explican por sí mismos los ritmos de los procesos (pre)históricos, especialmente los de transición / cambio / sustitución de entidades culturales, incluso aunque estén atestiguados por otros medios (estratigrafía, cultura material...), pues las escalas (más específicas las segundas y más genérica la primera) no son equiparables. Por ello uno de los intereses del trabajo, no el único como se verá, es reflexionar sobre el valor de las series de C14 en relación a la evolución del poblamiento y demografía.

En este sentido, los análisis cronológicos del C14, más al trabajar con fechas calibradas, son de carácter estadístico y no histórico. Para superar las diferencias entre ambos planos, y mejorar la evaluación del pasado, hay que establecer un diálogo permanente entre las muestras y su contexto arqueológico, preguntándose: para qué datar, qué datar, cuántas veces datar... El diálogo anclará las dos variables, comprendiendo que la muestra es producto de una acción humana que junto con otras configuraron el contexto arqueológico y considerando que en la elección de lo datado intervienen factores tales como la actitud del arqueólogo.

Debatiremos sobre la tendencia del poblamiento prehistórico ibérico desde la perspectiva cronológica: con bastantes dudas y entendiéndolo como el resultado de un número indeterminado de acciones humanas (las datadas) encadenadas sobre el tramo cronológico analizado. En el apartado correspondiente mostraremos las posiciones divergentes en donde se posicionan los autores, validando unos el trabajo con series de c14, poniendo, otros, en entredicho las resoluciones obtenidas. Quedarían por examinar los vínculos entre los resultados y las evoluciones culturales, las cuales no tienen por qué seguir necesariamente un recorrido lineal en escalas geográficas amplias: es una empresa que en este trabajo no podemos abordar.

Jerarquizamos los temas del presente estudio presentando en primer lugar los materiales y métodos. Posteriormente relacionamos una serie de problemáticas referidas al uso del C14, como paso previo a la explotación de los datos que son discutidos en unos apartados finales. Para aligerar el cuerpo central de nuestras argumentaciones, diversos análisis son explicados en el material complementario

\section{MATERIALES Y MÉTODOS}

Como herramienta para aproximarnos al conocimiento de la evolución del poblamiento en el 155005500 cal BP de la península ibérica, hemos implementado una base de datos de c14 con 1.393 muestras. Para Williams (2012) trabajar con menos de 500 dataciones da carácter provisional a las conclusiones; Mi- 
chczynska et al. (2007) proponen un mínimo de 780 para obtener deducciones fiables, cómputo no siempre alcanzado (Wicks y Mithen, 2014). Nuestra elección del tramo temporal se debe a que en él se: a) da la transición Pleistoceno-Holoceno, con cambios en las estrategias de los grupos humanos; b) desarrollan distintos complejos industriales del Mesolítico; c) conoce la transición hacia el Neolítico. Al involucrar a distintos periodos se nos ofrece la oportunidad de ver cómo las nuevas estrategias de las comunidades humanas influyen en lo que datan los arqueólogos y, por tanto en las SCDPD y su interpretación.

Para contrastar y ampliar el análisis ponemos a disposición más de siete mil dataciones del proyecto de Alday y Mejías: https://sites.google.com/ehu.eus/ c14peninsulaiberica. Para este artículo hemos utilizado 1,395 dataciones porque: bastantes de las del repertorio general desbordan el marco cronológico a estudio; otras se han publicado con posterioridad a la elaboración del trabajo; algunas no parecen relacionarse con contextos arqueológicos claros (por ejemplo, carbones de los pisos inferiores de megalitos). Las dataciones que utilizamos son las que conocíamos al iniciar nuestro trabajo, pero un mayor número no altera los resultados generales.

El catálogo reúne resultados obtenidos de: a) materias de distinta naturaleza (huesos humanos y de fauna salvaje o doméstica, madera/carbón, semillas, conchas...); b) muestras individuales o agregadas; c) procesadas en laboratorios con tratamientos diferenciados; d) yacimientos de diferente tipología y usos; e) con casuísticas particulares (por ejemplo en cuanto al número de veces que se data un lugar material complementario 1 (en https://sites.google.com/ehu.eus/c14peninsulaiberica/poblamiento-prehistorico-de-la-peninsula-iberica).

No incluimos los valores con desviación estándar superior a 100, ni algunas pocas muestras cuyo origen antrópico es discutible (verbigracia de Peña Oviedo obtenida de un carbón derivado de un incendio natural cuyo valor se aleja varios milenios de la estructura megalítica). Prescindir de fechas con alta desviación estandar es un problema menor (en ocasiones se trabaja con desviaciones de hasta 300 años -Zahid et al., 2015), porque: a) supondrían un pequeño porcentaje; b) imputarían principalmente a la cornisa Cantábrica para episodios del final del Paleolítico.

Se han calibrado las fechas con Oxcal v.4.2.3 en IntCal13, teniendo en cuenta el efecto reservorio para las muestras sobre conchas, atendiendo a los datos publicados. Se consideran los resultados a 2 sigmas. No se han aplicado técnicas estadísticas que combinan fechas de un mismo contexto o que relacionan diferentes unidades de un mismo lugar. Son procesos accesibles y viables (Bayliss y Woodman, 2009; Buck et al., 1991; Wicks y Mithen, 2014), pero dado que nuestro repositorio combina yacimientos con muy distintas problemáti- cas estos ejercicios pierden eficacia: a) lugares estratificados con dataciones susceptibles de combinarse; b) depósitos estratificados con pocas fechas y sin clara relación entre ellas; c) campamentos al aire libre donde los contextos son unidades estratigráficas (no niveles) cuyas relaciones son complejas (frecuentemente se datan elementos de relleno de estructuras negativas amortizadas); d) concheros con respaldos sedimentarios discutidos... Consideramos que lo coherente es tratar a todos los yacimientos por igual (Crombé y Robinson 2014) para eliminar los prejuicios sobre sitios o fases. Algunos autores prefieren usar una sola fecha por unidad arqueológica (Blockley, Donahuea y Pollarda, 2000; Housleya et al., 1997...), pero se ha advertido del valor limitado de estos ejercicios (Wicks y Mithen, 2014).

Generamos las SCDPD siguiendo los protocolos habituales (Balsera et al., 2015; Bernabeu et al. 2016 ...), pero con ciertas variaciones (Alday et al., 2018) para contrarrestar el problema de la sobrerrepresentación de dataciones de un mismo contexto (Crombé y Robinson, 2014; Attenbrow y Hiscock, 2015) que, de no evitarse, condiciona la estructura de los histogramas. Primero calibramos las fechas y seguidamente cada resultado es ponderado en relación al todo siguiendo la propuesta de Evin y colaboradores (Evin, Fortin y Oberlin, 1995). Para evitar la reiteración de fechas de un yacimiento en cada paso de tiempo de 50 años (dos generaciones en las que, de alguna manera y si fuera el caso, deberían reflejarse los cambios culturales) un algoritmo selecciona el valor de la función de densidad de la ponderación de la fecha más precisa. Así, todas las fechas son consideradas y estandarizadas, pero entre las solapadas de un yacimiento se atiende, en cada paso de tiempo, a la función de densidad de probabilidad más precisa. Los histogramas resultan de la suma de todos los valores considerados en cada paso de tiempo. Algunos autores han observado que el número de fechas por sí mismo puede inducir a errores y proponen cotejar las SCDPD con el número de yacimientos conocidos, datados o no (French y Collins, 2015; Solheim y Persson, 2018): nosotros recogemos esa problemática reconvirtiendo los datos cronológicos en unidades de actividad (material complementario 2).

Limitación común a todo sistema de compilación de dataciones es el trato homogéneo de los depósitos: no se tienen en cuenta ni la variedad e intensidad de las actividades, ni su tamaño, ni el número de personas que lo ocuparon... La problemática no se puede corregir en la construcción de las SCDPD pero debiera paliarse a partir del conocimiento detallado de los yacimientos y sus contenidos.

Asumiendo que el registro arqueológico está afectado por sesgos tafonómicos, hemos aplicado la fórmula de Surovell et al (2009): como veremos no obtenemos mejoras significativas en los resultados (Zahid et al., 2015), quizá al ser necesario unos mínimos de conocimiento del poblamiento al aire libre, factor que no se cumplen en la península ibérica. 
Analizaremos la información a escala peninsular y regional: las regiones se han acotado bajo criterios de áreas naturales y de investigación: cornisa Cantábrica, cuenca del Ebro, Meseta, Cataluña, Valencia, Andalucía y Portugal. Puede discutirse en casos la conveniencia de ubicar los sitios en una u otra región (incluir los del Valle de Ambrona en la cuenca del Ebro por cercanía y proximidad cultural; los de La Uña y La Braña en la cornisa Cantábrica; subdividir Portugal...). La participación de cada región en el conjunto es irregular (material complementario 3), más si atendemos a la extensión abarcada por la dispersión de los yacimientos.

Los yacimientos están georeferenciados, de manera que con el programa QGIS (versión 3.03) se realiza la base cartográfica. A diferencia de lo que es usual en nuestra disciplina, nosotros no consideramos un yacimiento como un punto inerte en el espacio, sino que lo vinculamos al territorio de explotación que le da sentido. Por eso los mapas de calor que se incluyen se han construido atendiendo a la cuadrícula de 10 kilómetros de lado en el que se encaja cada registro arqueológico: de esta manera, pensamos, se logra una mejor lectura de la verdadera ocupación del territorio ibérico.

\section{PRIMERA PROBLEMÁTICA. RADIOCRONOLO- GÍA Y YACIMIENTO}

El soporte teórico de los ejercicios que identifican frecuencia de valores C14 con poblamiento descansa en la idea de que las muestras son, generalmente, producto de algún tipo de actividad humana, que el método encuadra cronológicamente. La premisa es cierta, como lo es también que la suma de los valores de un contexto no reflejará toda la actividad desarrollada, sino solo de aquellas seleccionadas para su encuadre temporal.

Pero no todos los yacimientos son susceptibles de ser datados por igual: en el ámbito espacial y cronológico que tratamos hay un buen número de casos donde la escasez, y mal estado de conservación, de los restos orgánicos ha limitado o impedido la obtención de muestras. Estos yacimientos no lograrán, o lo harán parcialmente, su reflejo en los histogramas de distribución. En este sentido se ha señalado (Crombé y Robinson, 2014) que en Europa central es más complicado disponer de buenos contextos mesolíticos (por severos problemas de bioturbación) que de los grupos neolíticos LBK / BQY (normalmente fechados por múltiples muestras). Además, el tipo de actividad desarrollada por una comunidad determina las posibilidades de datación (Torfing, 2015). Un yacimiento de superficie de un grupo que acumula los residuos en pozos o fosas tendrá más posibilidades de ser datado, repetidamente, que el de aquella comunidad que abandona sus basuras al aire. Es, por ejemplo, la oposición que se da entre campamentos mesolíticos y neolíticos: los segundos son más fáciles de identificar y de datar que los primeros (y estarán mejor representados en los his- togramas): aquí probablemente la oportunidad de los datos más que la realidad prehistórica determina el resultado de los histogramas.

La posibilidad de datar un yacimiento (y el número de veces que se hace) depende de su proceso de formación-conservación y de su variabilidad interna. Así, referido al Neolítico, la primera razón explica el alto número de estructuras megalíticas datadas frente a yacimientos contemporáneos menos visibles (los poblados); la segunda revela el porqué de la diferencia de valores radiocronológicos publicados para enterramientos colectivos frente a las inhumaciones simples. Ambas razones desaconsejan, para este trabajo, considerar los yacimientos funerarios colectivos: cuya irrupción tiene lugar a finales del periodo analizado, se localizan aislados de los poblados y responden a una dinámica socioeconómica nueva. En cambio, sí recogemos las sepulturas individuales previas generalmente integradas, o muy vinculadas, a los lugares de habitación.

Recalcamos la idea de que el resultado de una analítica C14 no representa el total de la formación y vida del relleno arqueológico de la muestra: tan solo indica el espacio temporal en que una acción tuvo lugar. Por tanto, tampoco la suma de muestras, representa la integridad de nivel. Visto así, los ejercicios que compilan las fechas de un contexto para acotar su formación corren el riesgo de sustraer y centrar la realidad del estrato, dejando fuera sus extremos. Aunque el método radiocronológico es absoluto en su concepción, en su relación con el contexto ofrece una respuesta relativa, y el uso de algunos criterios estadísticos puede ahondar en dicha problemática.

\section{SEGUNDA PROBLEMÁTICA. LOS AJUSTES DE LA TÉCNICA DEL C14}

Los resultados radiocronológicos incluyen una estimación y una desviación estándar presentándose como una función modal. El traslado de la edad isotópica a calendárica obliga a calibrar el valor, resultando una función plurimodal de distribución asimétrica que dificulta la lectura del hecho arqueológico. La mecánica de calibración ofrece valores diferenciados según el método empleado (al respecto es muy interesante el trabajo de Weninger et al. 2011). Entre las 1.393 fechas de nuestro catálogo la longitud media de las muestras calibradas es de 310 años usando Calpal (valor mínimo de 80 años y máximo de 1040) y de 294 utilizando Oxcal (entre 55 y 1000 años). Las diferencias son más notables al cotejar una a una las fechas o según milenios (material complementario 4): así, entre el 11000 y el 10000 cal BP el recorrido medio es de 457 años (oxcal) que se eleva a 611 en el siguiente milenio.

La calibración aumenta las incertidumbres de los resultados, y su compilación implica la suma de estas irregularidades (Barceló, 2008), se haga por regre- 
sión o por interpolación (Blaauw, 2010 para su crítica). Las rutinas más usadas son Calpal y Oxcal (Weninger y Jöris, 2004), pero hay otras opciones: Bcal, Calib o clam (Blaauw, 2010). Los sistemas deben entenderse como alternativas (ante la complejidad de los procedimientos), y todos alargan la longevidad de los procesos culturales (Aranda y Lozano, 2014; Barceló, 2008) y suavizan la transición de los procesos (pre)históricos.

Problema añadido son las irregularidades de la curva de calibración (sus mesetas, escalones y valles -Guilderson, Reimer y Brown, 2005), para las que se han realizado algunas propuestas de corrección (Williams, 2012). Para nuestro periodo de análisis las principales mesetas se dan en los tramos 12420-10720 cal BP, 8990-8650 cal BP y 6690-5540 cal BP. Podemos observar el fenómeno en la serie de Atxoste: a) su transición mesolítica/neolítica está enmarcada por las fechas del $6940 \pm 40$ y $6220 \pm 60$, ofreciendo la calibración de la primera una amplitud de 200 años, que es duplicada en la segunda por efecto de una meseta de la curva de calibración; b) sus cuatro fechas del IX milenio (BP) se asocian a otra meseta que alarga la vigencia de cada una al menos cuatro siglos, periodo donde se encadenan las unidades mesolíticas microlaminar y de muescas y denticulados. En ambos casos tendremos dificultades para concretar las transiciones culturales y el poblamiento (material complementario 5).

En la curva de calibración también se han identificado 10 saltos en el Holeceno (Michczynski et al., 2007; Williams, 2012) siendo significativos para nosotros los habidos en 12620-12550 cal BP, 11270-11180 cal BP; 10240-10120 cal BP; 9560-9470 cal BP y 5930-5590 cal BP. En casos coinciden con picos en las SCDPD, a valorar al interpretar los histogramas. También se ha observado una tendencia a la comprensión artificial de las dataciones entre el 5500-5300 y el 5200-5000 cal BP (Oberlin, 2003). En el material complementario 5 identificamos algunas de las perturbaciones de IntCal13 y su relación con nuestros datos, especialmente en 12.1, 10.5, 9.5 y 8.4 ky cal BP.

\section{TERCERA PROBLEMÁTICA. CORRELACIÓN ENTRE TIPOS DE MUESTRAS}

De seguir algunas propuestas referentes a las muestras que deben de ser aceptadas o rechazadas deberíamos prescindir de más de medio millar de los valores: especialmente las dataciones sobre carbón. (Bernabeu et al., 2014; Cortés et al., 2012; Drake, Blanco y Lillios, 2016; Martins et al., 2015; Pardo et al., 2015). Al respecto recordemos que antes de la puesta al día del procesado por AMS el carbón vegetal era el material preferente para datar dada la mayor facilidad para extraer el c14 frente a la madera o al hueso. La generalización del uso del AMS solventó algunas de las barreras entre los tipos de muestra, pero quedan sin resolver problemas varios: carbones que no reflejan realmente el cuándo del uso de la madera, o las dife- rencias de lecturas entre huesos de un mismo esqueleto por sus estructuras y ritmos de remplazo del c14 del colágeno (Calcagnile et al. 2013; Hedges et al. 2007; Ubelaker et al. 2006).

Nuestro repositorio combina muestras de vida larga (42\%, 170 yacimientos) y corta (46\%, 255 yacimientos) -para algunas muestras no hay información disponible. Hemos tratado independientemente cada serie, observando que las curvas de distribución de las frecuencias de probabilidad sumada son muy similares (material complementario 6): de hecho pruebas estadísticas les otorgan un coeficiente de correlación de 0,92. Hay una lógica humana en este hecho: la recolección de leña como combustible tenderá a acumular madera seca caída anualmente, fácilmente transportable por cualquier miembro de la comunidad. No parece oportuno proveerse de grandes troncos (difíciles de abatir con el instrumental prehistórico) salvo en labores de construcción: el cocinado de alimentos, razón de la mayor parte de las hogueras, no necesita de gruesos troncos, en estas circunstancias el factor de la madera vieja es un problema menor. En esta línea es concluyente el trabajo sobre el yacimiento de La Draga que observa que los numerosos troncos recolectados para las infraestructuras domésticas no alcanzaban los 35 años de vida (Tarrus, 2008). Por tanto, frente a las prevenciones sobre el trabajo con muestras leñosas que pudieran arrastrar el fenómeno de madera vieja (no se podrá negar que en casos el problema es real), parece lícito usar en conjunto ambas series.

Por otra parte, la correlación de las series tratadas mediante tecnología convencional frente a AMS no manifiesta ventaja alguna para estas últimas (Barceló, 2008). En cuanto al hueso quemado se ha indicado que se trata de un material muy adecuado para la datación (Rubinos, 2009. En relación a su problemática ver Olsen et al. 2013).

\section{DISCUSIÓN}

\subsection{Valores radiocronológicos y poblamiento}

El perfil de las SCDPD se viene utilizando como método de evaluación del poblamiento y la demografía en un tiempo y una geografía determinada (Rick, 1987; Crombé y Robinson, 2014): los ascensos de las curvas se entienden como aumento de población y los descensos como pérdidas. Se ha señalado que los resultados suelen originar falsos positivos y las interpretaciones pueden alejarse de la realidad histórica (Contreras y Meadows, 2014). Nosotros también pensamos que las SCDPD deben ser consideradas como herramientas limitadas en la interpretación del poblamiento al estar determinadas, al menos, por los siguientes factores.

a) la relación de las muestras con los hechos arqueológicos;

b) el método del C14, su calibración y los procesos de compilación de los valores; 
c) el sesgo tafonómico y su afección en la conservación de los yacimientos;

d) el sesgo de la investigación que enfatiza el estudio de unos elementos y épocas;

e) los cambios en las pautas de subsistencia y, en relación a ello, de los patrones de movilidad.

En vista de los factores que intervienen es necesaria la crítica que valore en qué medida su construcción se relaciona con el poblamiento y la demografía. Williams (2012), Surovell y Brantingham (2007), Peros y colaboradores (2010) o French y colaboradores (2015) consideran plausible dicha relación corregido el sesgo tafonómico. Torfing (2015) no cree adecuada esa traslación al estar afectadas las curvas por agentes no históricos, derivados del registro arqueológico y considera, volteando la argumentación, que lo que realmente observa una serie C14 son los elementos que intervienen en la formación y conservación de los yacimientos. Nos posicionamos en esta línea considerando, desde un plano teórico, que una proporcionalidad directa entre SCDPD y poblamiento sólo sería aceptable si la duración de las ocupaciones y las pautas de movilidad de las sociedades fueran constantes a lo largo del periodo de estudio. Una modificación de esas estrategias reflejaría falsos positivos/negativos. Las frecuencias de las fechas C14 reflejarían la evolución demográfica si a) sus incrementos son acordes con un crecimiento biológico aceptable según los regímenes económicos de cada fase; b) los incrementos superan la capacidad reproductora pero son conocidas situaciones de llegadas de nuevas poblaciones (inequívocamente plasmadas en el registro arqueológico); c) los descensos poblacionales se justificaran por causas plausibles (epidemias, hambrunas, problemas climáticos...).

El debate origina posturas difíciles de conciliar (Gkiasta et al., 2003; Riede y Edinborough, 2012; Weninger et al., 2009; Wicks y Mithen, 2014; Solheim y Persson, 2018). Un ejemplo reciente es el cotejo de las posturas de Attenbrow y Hiscock (2015) -no consideran el cálculo de distribución de probabilidad sumada C14 un método robusto para evaluar el tamaño de la población prehistórica- y de Williams y Ulm (2016) -que validan los resultados-.

Hay que retener que un crecimiento de población no tiene por qué generar un aumento del número de yacimientos: ocurrirá cuando el grupo se sitúe en el punto crítico que le obligue a su división al peligrar su estabilidad o viabilidad socioeconómica. Además, según las estrategias de explotación seguidas, cada grupo generará en un territorio diversos tipos de yacimiento (no todos igual de visibles): cambios en los modelos de subsistencia y/o de movilidad alterará la ratio grupo/número de yacimientos. Por ejemplo, tanto en el oriente de la cornisa Cantábrica como en Cataluña se ha puesto de relieve la existencia de un cambio en las estrategias organizativas de las sociedades Azilienses-Epipaleolíticas respecto a las de finales del Magdaleniense. En varios yacimientos
-Santa Catalina, Laminak II, Berniollo, Portugain, para el País Vasco y Parco en Cataluña-, se intuye cierta tendencia hacia la fragmentación de las actividades sobre asentamientos con funcionalidades distintas, con un patrón de movilidad circunscrito a un territorio más pequeño pero intensamente explotado (Calvo et al., 2009; Ibañez y González, 1998; Mangado et al., 2005; Terradas et al., 2007). Esta complementariedad entre asentamientos y de rupturas en los procesos de transformación también ha sido reconocida en la vertiente septentrional de los Pirineos (Philibert, 1995). ¿Implica la activación de mas lugares por un mismo grupo respecto al periodo previo? Más adelante una de las particularidades del poblamiento prehistórico holocénico de Iberia es su organización en redes social y económicamente eficientes, habiendo evaluado su variabilidad en sucesivas unidades culturales (Montes y Alday, 2012).

\subsection{Los sesgos de la información}

Las series de radiocarbono para inferir dinámicas de poblamiento se enfrenta a potenciales sesgos, siendo necesario desarrollar y probar métodos de corrección.

Uno de los sesgos tiene que ver con los programas de investigación. Así, referido a la transición Mesolítico - Neolítico de la península ibérica en general, y de la cuenca del Ebro en particular, el registro arqueológico revela como prospecciones temáticas y/o geográficas junto a políticas de prevención incrementan notablemente la información. Las estrategias de búsqueda, sondeo y excavación de abrigos han mejorado el catálogo, pero también lo han enfocado en exceso hacia un tipo de yacimiento. Quizá variando los protocolos de investigación seríamos capaces de mejorar y diversificar el registro, tal y como se ha logrado, por ejemplo, en el Valle de Ambrona (Rojo et al., 2008). Aquitania - Midi-Pyrénées es un buen espejo donde mirarse: las políticas de gestión patrimonial han permitido que en los últimos años el 95\% de los hallazgos paleolíticos sean lugares al aire libre en zonas llanas, en oposición a la tradicional ocupación en cuevas de ambientes abruptos (Bourguignon, 2010; Ducrocq, 2010), antes considerada como la propia de los grupos. En este sentido, son de agradecer los trabajos como los realizados en el conchero en cueva de Alloru, que muestran como la ocupación desborda el tamaño inicialmente considerado y señalan la complejidad del lugar (Arias et al., 2015): en no pocas ocasiones nuestra visión del pasado es excesivamente plana.

Attenbrow y Hiscock (2015) han señalado como sesgos de investigación la tendencia a la excavación de los yacimientos mejor conservados (más rentables), o la selección de las muestras susceptibles de acotar la mayor antigüedad del sitio (frente a momentos intermedios o finales). Son problemáticas sistémicas entre los arqueólogos.

Un sesgo de carácter histórico se relaciona con cambios en la subsistencia y su repercusión en los 
patrones de poblamiento (Crombé y Robinson, 2014; Torfing, 2015). Tenemos un la península unos buenos ejemplos en los concheros: en su versión tradicional campamentos al aire libre en playas- o más específica -cuevas de la cornisa Cantábrica -Fano, 1998)-. Fenómeno económico del Holoceno es la intensificación del marisqueo, actividad que da sentido al complejo asturiense cantábrico o que visualiza la económica del Mesolítico y primer Neolítico de buena parte de Portugal (Bicho et al., 2010). También es una actividad bien reconocida en costas europeas y africanas (Dupont y Marchand, 2016).

Reconociendo sus potencialidades socioeconómicas, es apropiado preguntarse sobre en qué medida la emergencia de este modelo repercute en las SCDPD. La explotación intensiva de los entornos costeros y marismeños entrega un tipo de yacimiento que, una vez estabilizado, se conserva muy bien. Se caracterizan, además, por: a) ubicarse en suelos arenosos que la erosión visualiza; b) ser accesibles de manera que en varias regiones los inicios del conocimiento del pasado prehistórico tiene mucho que ver con sus descubrimientos; c) ser llamativos por sus residuos; d) formar parte de un esquema económico complejo de alta movilidad con régimen estacional (Cubas et al., 2016); e) proporcionar un buen número de elementos susceptibles de datarse. Por todo ello es posible que su alta frecuencia proporcione una imagen de sobreexplotación de los litorales, en detrimento de otras acciones paralelas menos visibles. De hecho, a tenor de sus rellenos, los concheros no reflejan la totalidad de las actividades de los grupos (datos parciales de caza, recolección, producción...).

Desde nuestro punto de vista los concheros constituyen un buen ejemplo de cómo yacimientos muy visibles, especializados y fáciles de datar influyen en el dibujo de las SCDPD: informan sobre los intereses económicos de los grupos, pero no claramente sobre los regímenes de poblamiento/demografía.

Otros sesgos derivan de aspectos sociales de las comunidades: por ejemplo, la monumentalidad funeraria del neolítico avanzado. El hallazgo de sepulcros megalíticos constituyó en muchos rincones el inicio de la disciplina prehistórica, y su estudio ha centrado buena parte del quehacer de los investigadores. Su visibilidad se opone al vacío documental de los contemporáneos lugares de habitación. Torfing (2015) demostró la no conveniencia de tenerlos en cuenta al analizar el poblamiento desde la perspectiva radiocronológica. Nosotros argumentamos su exclusión porque: a) su visibilidad facilita su descubrimiento sobredimensionando su influencia; b) son espacios independientes del verdadero poblamiento; c) en su uso hay connotaciones de edad y género que no los hace representativos del total de la población; d) son de utilización prolongada pero discontinua siendo difícil desentrañar la dinámica funeraria.

Mas razones invalidan la asimilación entre radiocronológica y poblamiento: a) metodológicas: el C14 concreta el tiempo de una acción antrópica (quema de una madera, caza de un animal, consumo de un vegetal, muerte de un individuo...) pero no la totalidad del contexto arqueológico donde dicha acción se inserta. En consecuencia, es referencia relativa del contexto que puede ofrecer otros resultados cronológicos solapados, continuos o distanciados; b) de oportunidad: solo pueden datarse los contextos que han perdurado y tengan elementos orgánicos que cumplen determinadas condiciones

\section{EXPLOTACIÓN DE LOS DATOS}

\subsection{El caso peninsular}

Con las 1.395 dataciones hemos realizado distribuciones de probabilidad sumada en pasos de tiempo de 50 años (figura 1). Como alternativa ofrecemos los datos en pasos de 200 años (material complementario 7).

Al estar los yacimientos están georeferenciados, con el software QGIS, hemos realizado el levantamiento cartográfico que ilustra el trabajo, considerando periodos de un milenio: la compilación en milenios tiende a ampliar cronológicamente la actividad de cada sitio, suavizando las transiciones (Bernabeu et al., 2014; Bocquet-Appel et al, 2012; Fano, Cubas y Wood, 2015; Fort, 2015; French y Collins, 2015; Johnson y Brook, 2011; Porčić et al., 2016; Rocha, 2003; Shennan et al., 2013; Tallavaara et al., 2015)

En la SCDPD parte de las oscilaciones se relacionan con las irregularidades de la curva de calibración (Guilderson et al., 2005). Ya hemos señalado cuáles son las mesetas, saltos y compresiones que afectan al periodo (Michczynski et al., 2007; Williams, 2012). En material complementario 5 se identifican las perturbaciones más notorias para nuestros datos: en ky cal BP $12.1,10.5,9.5$ y 8.4

Se observa una primera fase de incremento lento pero progresivo de las frecuencias hasta el inicio del Younger Dryas (YD): son los últimos compases del Magdaleniense y los primeros del epipaleolítico. La caída de la curva c. 12700 cal BP y su mantenimiento hasta c. 10600 cal BP coincide con una meseta de calibración, complicando la visualización cronológica de los contextos en la transición Pleistoceno-Holoceno. No obstante juega a favor de una mayor actividad humana el amejoramiento climático anterior al YD. Referido a las industrias asistimos al desarrollo de conjuntos microlaminares (sensu lato) en sus distintas versiones.

La tendencia se revierte con un fuerte incremento de las frecuencias c. 9500 cal BP, momento de generalización del Mesolítico de muescas y denticulados, coincidente con un periodo de estabilidad climática (Carrión et al., 2010; Cortés et al., 2012; Fernández y Gómez, 2009; González-Sampériz et al., 2009; Iriarte, 2009, 2006; Lillios et al., 2016; López Sáez et al., 2008). Apuntamos como hipótesis que la densa cobertura forestal compartimentó los territorios provocando un au- 


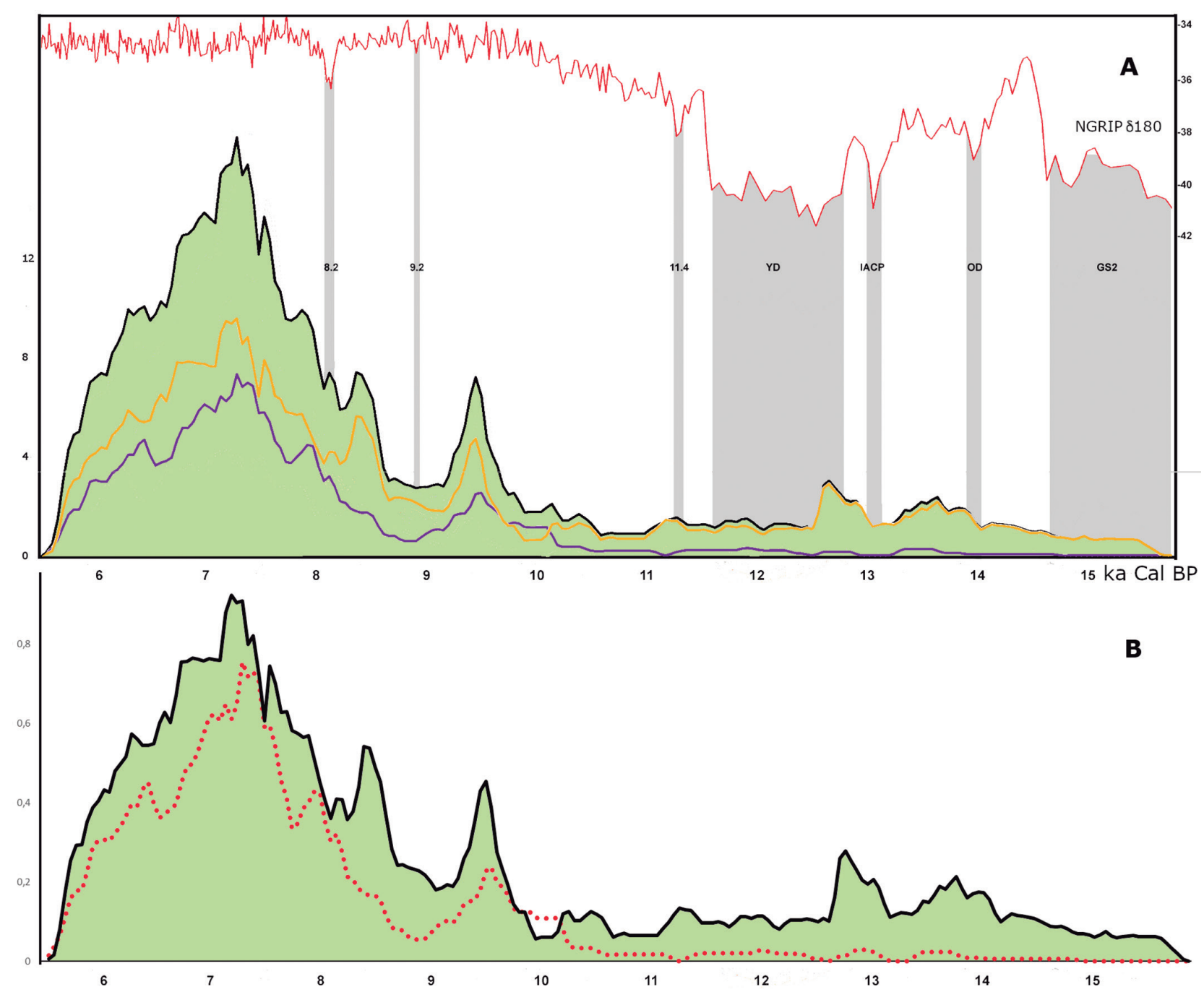

Fig. 1. A: Línea superior SCDPD de los 317 yacimientos; intermedia SCDPD de yacimientos en cuevas y abrigos (185 sitios, 824 fechas); inferior SCDPD de lugares al aire libre $\left(128,571\right.$ fechas). La relación $n^{\circ}$ de yacimientos / $n^{\circ}$ de fechas es de 4,451 para los refugios y 4,46 para los depósitos de superficie: B.SCDPD aplicando la fórmula del sesgo tafomómico de Surovell et al. 2009: el perfil de la curva no varía en sus tendencias respecto a la normalizada. En este y en gráficos similares el eje de ordenadas señala la cronología en años cal BP por mil; el eje de abcisas la densidad de fechas. Línea roja: evolución climática segín NGRIP 018./ A: upper line SCDPD of the 317 sites; intermediate line SCDPD of caves and shelters (185 sites, 824 dates); lower line SCDPD of surface deposits (128 sites, 571 dates). The number of deposits / number of dates is 4,451 for shelters and 4,46 for surface deposits: B.- SCDPD applying the formula of the taphomomic bias (Surovell et al. 2009): the profile of the curve does not vary in uss tendencies with respect to the normalized.

mento en el número de establecimientos. Pero también es clara una alteración en IntCal13 que agudizaría el pico de los histogramas. En muchos casos este es el único momento de ocupación de un lugar (Marge del Moro, Barco do Xarez de Baixo, Parque Darwing, Las Orcillas, Vale Frade) o el de su inauguración (Fraga d'Aia, El Toral III, El Tossal de la Roca, Buraca Grande, Barranco do Quebradas, Canalejas 2...). Aunque la ocupación en abrigos es mayoritaria se incrementan los lugares al aire libre sea por el fomento de concheros o por el hallazgo de estaciones en áreas antes carentes de información (Artegieta en el Cantábrico, Font del Ros en el Ebro, Parque Darwin y Calvera en el interior...).

Se constata c. 8500 cal BP un nuevo incremento a diferencia de lo observado en otras regiones europeas (Timpson et al., 2014): el comienzo del ciclo se corres- ponde con el proceso de regionalización que proponen la distribución de las armaduras (Utrilla y Montes, 2009). Aún incrementándose los lugares al aire libre son duplicados por los registros en refugios (3 decenas frente a 6). La dinámica ascendente continúa para alcanzar los valores más altos en las primeras centurias del Neolítico. Esta evolución durante el último episodio Mesolítico y primeros siglos del Neolítico ha sido observada en trabajos peninsulares (Balsera et al., 2015; Bernabéu et al., 2016; Drake et al., 2016). No obstante a partir de finales del VII milenio cal BP comienza una brusca caída de los datos, en coincidencia con una nueva meseta (debiendo de tener en cuenta el condicionante de toma de los datos). Como vemos la SCDPD presenta un perfil algo diferente a la de otros territorios europeos (Shenan et al., 2013; Timpson et al. 2014), que han observado 
una pérdida de población durante el mesolítico, un aumento con la llegada de la economía de producción y una fuerte pérdida tras su primer impacto que no suele recuperarse hasta unos 800 años después (crítica en Crombé y Robinson, 2014; Torfing, 2015). El punto de inflexión entre el séptimo y sexto milenio no lo entendemos nosotros como fruto de una caída demográfica (Timpson et al. 2014), sino resultado de cambio en los patrones de asentamiento. Hasta entonces los contextos datados eran, mayoritariamente, cuevas y abrigos bajo roca (más concheros) frente a pocos yacimientos al aire libre. Mientras el modelo de habitat pervive en los inicios del Neolítico, el número de yacimientos datados sigue incrementándose: pero el abandono de los refugios (salvo por su uso como rediles) y de los concheros nos parecen posibles causas en el descenso los histogramas (Alday et al., 2018).

En general la SCDPD ibérica presenta numerosos dientes de sierra, más de lo esperable si reflejara el poblamiento: aunque hay autores que toman estas situaciones como resultado de factores poblacionales derivados de cambios climáticos o subsistenciales (Johnson y Brook, 2011; Robinson et al., 2013; Zahid et al., 2015), la realidad es que también actúan la oportunidad de los datos, la reconversión de la edad isotópica a calendárica y los cambios en las estrategias poblacionales.

\subsection{Vacíos y concentraciones: aportes de las curvas regionales a la construcción de la SC- DPD peninsular}

La dinámica descrita varía al analizar la situación por regiones, en parte por la irregular participación de cada territorio, en números absolutos y atendiendo a la extensión de dispersión de los yacimientos (material complementario 3). Hay tendencias comunes en las curvas pero también comportamientos específicos (Fig. 3) (material complementario 8).

La península ibérica prehistórica reunía una amalgama de situaciones climáticas, paisajísticas, geológicas, estructurales... que condicionarían los comportamientos humanos, adaptándose a lo que el medio les ofrecía. Además, cada cuenca, llanura, área montañosa... se ha visto afectada por particulares circunstancias geomorfológicas influyendo de manera desigual en la conservación de los yacimientos. La combinación de factores humanos y naturales sugiere que las frecuencias de C14 deben contrastarse región por región: cornisa Cantábrica, cuenca del Ebro, Cataluña, Meseta, Valencia, Andalucía y Portugal. En esta división, tomada como herramienta de trabajo y discutible como cualquier otra que la sustituyera, las fronteras serían permeables.

Considerando la localización geográfica de las referencias (figura 2a, 2b y 3) destaca la concentración en ciertas áreas (cantábrico oriental, cuenca del Ebro, Cataluña, Valencia, litoral central y sur de Portugal) y los vacíos en otras (interior peninsular, Andalucía, has- ta el final del periodo o Galicia). Obviamente el dibujo responde a la muy desigual distribución del registro arqueológico. Los ejercicios cartográficos como el presente son muy visuales, pero, técnicamente, reproducen las SCDPD enmascarando las perturbaciones de la curva de calibración: en este caso, por operatividad, los datos se reunen en milenios perdiendo precisión en la visualización de los fenómenos particulares.

La primera de las fases descrita para la curva ibérica -bajo incremento progresivo- está condicionada por el protagonismo del cantábrico, Ebro y Cataluña (figura 3). Se entiende que, en esta fase de amejoramiento climático, las áreas que a lo largo del Paleolítico superior actuaron como refugio poblacional (cornisa Cantábrica y Cataluña) son el motor de la colonización de las tierras circundantes: entonces la cuenca del Ebro se posicionará como núcleo cultural activo y relativamente homogéneo (Barandiarán et al., 2006). Fuera de estas áreas, y de focos menores en Portugal (Lapa do Picareiro, Caceço do Porto Marinho, Pedra do Patacho, Pinhal da Carreira), Valencia (Cendres, Tossal de la Roca y Santa Maira), o puntuales lugares -los organizados en torno a Estebanvela en la Meseta o Nerja en Andalucíael resto peninsular muestra un desconcertante vacío.

La imagen apenas varía durante el YD y los inicios del Holoceno, al no presentar el registro arqueológico cambios significativos (figura 3). Además, la influencia de una meseta en Intcal13 dificulta obtener una imagen más precisa de las frecuencias de dataciones de periodo: las curvas regionales con referencias presentan un descenso y aplanamiento (figura 2), y en la cuenca del Ebro se observa una pérdida de información, especialmente en su sector central. En contra hay un aumento de los datos en el norte y centro de la región valenciana (Casa Corona, Penya del Comptador, Tossal de la Roca...)-. Portugal presenta desde el 10500 cal BP su despegue definitivo con yacimientos aglutinados en torno a la desembocadura del Tajo (Buraca Grande, Fraga de d'Aia, Toledo, Pont da Vigia, Barca do Xarez de Baixo, São Julião)

Un cambio se reconoce en torno al 9500 cal BP, con el desarrollo del Mesolítico de muescas y denticulados. Hay una significativa concentración de dataciones en Portugal, cuenca del Ebro, cornisa Cantábrica y, moderada, en Valencia. Hemos señalado la posible influencia -sobrerepresentando- de un pico en la curva de calibración (también observado en regiones con dinámicas culturales muy diferentes, lo que debe hacernos reflexionar sobre las perturbaciones de la curva de Calibración -Solheim y Persson, 2018). En este sentido la caída c. 9000 cal BP se asocia a una meseta en IntCal13 que repercute en todas las regiones, con especial fuerza en Portugal (figura 2).

Es muy llamativo el incremento de la frecuencia de dataciones en c. 8500-7000 cal BP para todas las regiones, aunque variando los tiempos y la intensidad. La curva que mejor se ajusta al modelo general es la de 

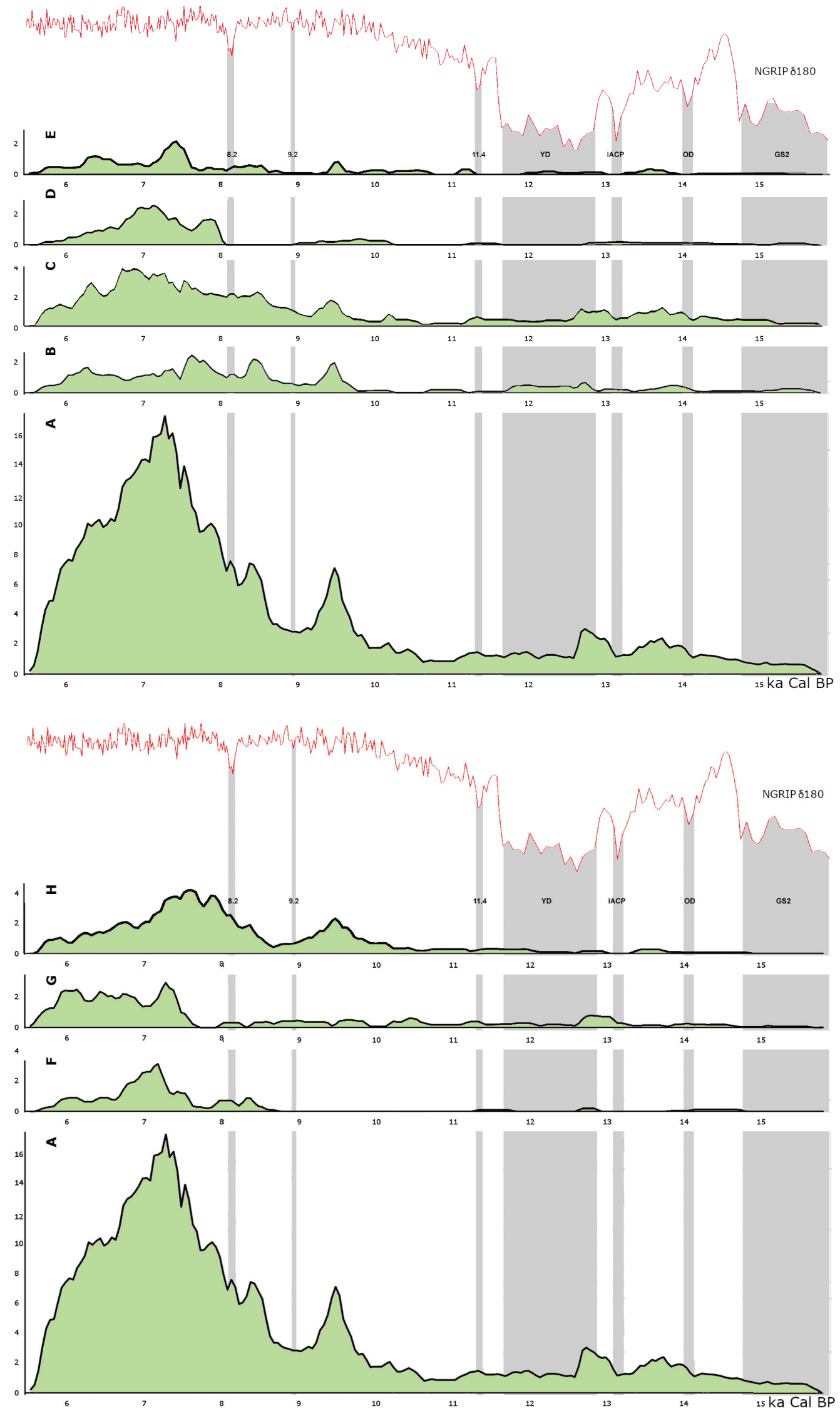

Fig. 2. SCDPD de A.- Península ibérica; B.- Cornisa cantábrica; C.- Ebro; D.- Meseta; E.- Valencia; F.- Andalucía; G.- Cataluña; H. - Portugal. / SCDPD of A. Iberian Peninsula: B - Cantabrian cornice; C.- Ebro; D.- Meseta; E.- Valencia; F.- Andalusia; G.- Catalonia; H.- Portugal. 


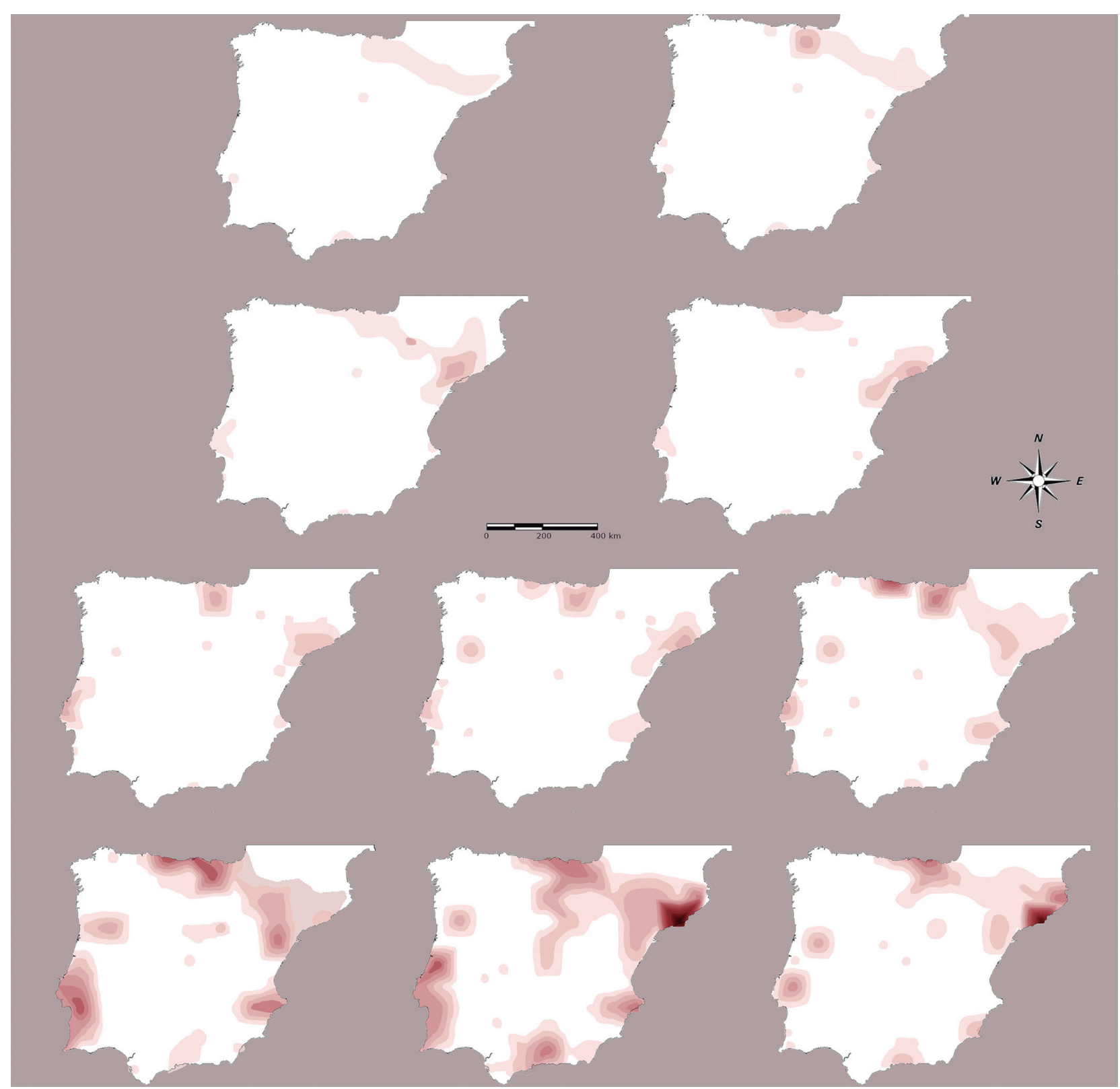

Fig. 3. Evolución cartográfica de los yacimientos datados mediante C14 de la Península ibérica por milenio y estandarizadas las dendidades. De arriba hacia abajo y de izquierda a derecha del 15500-14500 al 6500-5500. / Cartographic evolution of the deposits dated by C14 of the Iberian Peninsula.

Portugal: incremento c. 8700 cal BP para, tras un breve descenso, despuntar c. 7650 cal BP con su máximo c. el 7300 cal BP. En el Ebro y Cantabria la concentración de frecuencias en torno al 8500 coincide con los inicios del Mesolítico geométrico, pero mientras que en el Ebro el crecimiento se mantiene varios siglos después de la llegada del Neolítico, en el cantábrico c. 7600 cal BP tiene lugar un notable descenso hasta el final de la secuencia (Drake et al., 2016). Valencia y Cataluña destacan, contrariamente, por el bajo número de sus frecuencias en estos momentos (Bernabeu et al., 2016), con reseñable ausencia de datos en 8000-7600 cal BP en el segundo lugar (Morales y Oms, 2012; Vaquero y
García, 2009), coincidiendo la recuperación del 7600 con la identificación de las primeras evidencias neolíticas (Bernabeu et al., 2016; Drake et al., 2016). Es en esta transición cuando tanto Andalucía como la Meseta, en áreas muy determinadas, empiezan a aportar información significativa: en el interior por la ocupación del valle de Ambrona y del entorno Atapuerca-Pancorbo (Alonso, 2017; Rojo et al., 2008).

Finalmente, hacia el 7200-7000 cal BP se aprecian descensos en las frecuencias de dataciones en Portugal, Andalucía, Valencia, Cataluña, y algo más tarde en la cuenca del Ebro y la Meseta (7000-6800), continuando Cantabria con su particular dinámica. 


\subsection{La naturaleza del registro arqueológico o la variabilidad de la realidad prehistórica}

Observada la información por tipos de yacimiento también encontraremos situciones discrepantes. Hasta c. 10300-10000 cal BP los datos suponen un poblamiento datado centrado en las cavidades (figura 1). Desde ese momento participarán algunos pocos sitios al aire libre. En adelante, ambos modelos de asentamientos seguirán tendencias similares aunque con matices (figura 5) -especialmente en torno a la $8500 \mathrm{cal}$ BP -. Al estandarizar los datos al mayor valor de ambas series, se observa que los refugios superan a los depó-
Los yacimientos al aire libre intensifican su presencia desde el 10300-10000, espoleados a partir del 9500 por los conjuntos del Mesolítico de muescas y denticulados.

El descenso de fechas del 9000 cal BP afecta a todos los modelos de yacimientos, y la recuperación posterior viene principalmente de la mano de los refugios, no siendo hasta el 8200-8000 cal BP cuando los concheros portugueses y cantábricos ofrezcan nuevas referencias radiocarbónicas: también ahora la emergencia de conjuntos funerarios juega un papel reseñable (La Fragua, Covajorno, Santimamiñe, el Mazo, Tora-

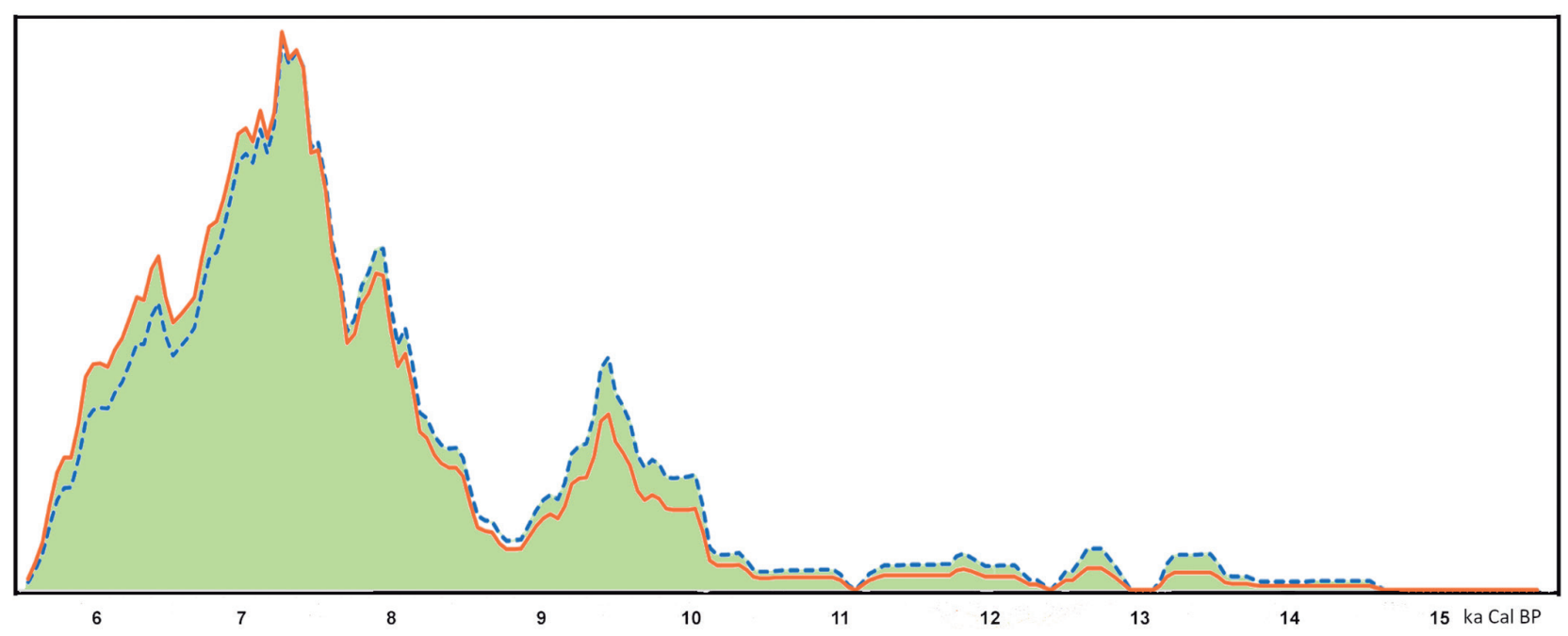

Fig. 4. SCDPD de los yacimientos al aire libre (en punteado corregido el sesgo tafonómico según la fórmula de Surovell et al. 2009 ). Datos estandarizado al mayor valor. / SCDPD of the open-air Iberian Peninsula deposits (with points corrected the taphonomic bias according to Surovell et al., 2009). Standardized data at the highest value.

sitos superficiales en todo el recorrido: solo en el octavo milenio ambos alcanzan por momentos similar representación, dada la emergencia de los concheros del final del Mesolítico. Es decir, se distinguen dos fases en la SCDPD ibérica: una donde las referencias son casi exclusivamente de refugios; y otras desde c. 10000 con participación de depósitos al aire libre, en su mayoría concheros, con rasgos de visibilidad y conservación muy específicos. Es evidente que la tafonomía influye negativamente en la conservación de los yacimientos al aire libre (material complementario 9), y la aplicación de la fórmula de Surovell et al. (2009) (figura 4) no mejora el panorama.

La proporción del tipo de yacimientos varía regionalmente (figura 5). Para el primer tramo de la SCDPD peninsular los sitios al aire libre son anecdóticos: salvo por Casa Corona (descubierto valenciano con ocasión de la construcción de una vía férrea), son concheros portugueses. De hecho, esta región tiene un comportamiento excepcional al ser la única donde, en términos generales, los yacimientos al aire libre superan a la ocupación en refugios (figura 5). lete, J3, la Garma...). Con el cambio de estrategia del poblamiento neolítico, el incremento de los poblados al aire libre será significativo: en la Meseta superaran a otros patrones de asentamiento, tendencia confirmada en Cataluña, Ebro, Valencia o Andalucía (figura 5).

Finalmente, el descenso del 7000 cal BP afecta a todos los tipos de yacimientos, si bien con problemáticas particulares: si de la cornisa Cantábrica o en Cataluña elimináramos las muestras sobre huesos humanos, la regresión sería más acusada; también es significativo históricamente el abandono de los concheros en Portugal; en la cuenca del Ebro la ocupación de abrigos sirve a la gestión ganadera.

Es importante recordar que en este ejercicio no hemos tomado en consideración las fechas de los recintos dolménicos, cuya construcción empieza a finales del período analizado. La abundancia y distribución de los panteones megalíticos evidencia, como contrapunto, que a pesar de la pérdida de información en los lugares de habitación el poblamiento peninsular seguía siendo muy denso, aunque de visualización opaca desde la perspectiva radiocarbónica. 

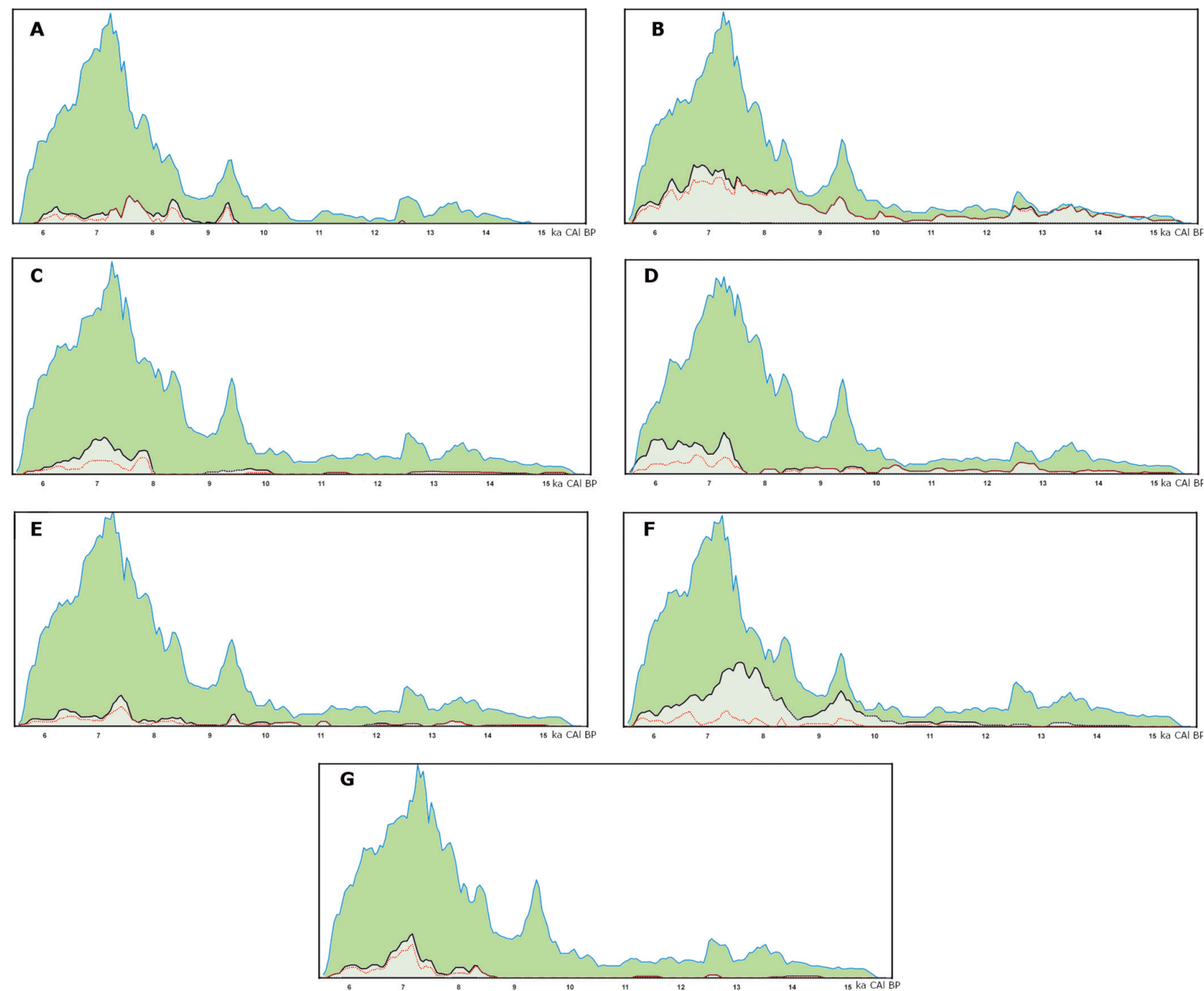

Fig. 5. SCDPD Regionales. A. - Cornisa cantábrica; B - Cuenca del Ebro; C. - Meseta; D. - Cataluña; E.- Valencia; F.- Portugal; G. - Andalucía. En cada figura la línea superior es el perfil de la SCDPD de todos los yacimientos ibéricos excluídos los de la región; la segunda línea representa la contribución de la región; la primera línea punteada representa la contribución regional de las cuevas; la última línera representa a la contribución regional de los asentamientos al aire libre. / Regional SCDPD. A.- Cantabrian Cornice; B.- Basin of the Ebro; C.- Meseta; D.- Catalonia; E.- Valencia; F.- Portugal; G.- Andalusia. In each figure the upper line is the profile of the SCDPD of all the Iberian deposits excluded from the region; the second line represents the contribution of the region; the line whith points represents the regional contribution of the caves; the last line represents the regional contribution of the open-air settlements.

\subsection{La naturaleza del registro arqueológico o la variabilidad de la realidad prehistórica}

Como se observa en la figura 1, no es sencillo asociar la SCDPD con las pulsaciones climáticas, salvo tal vez el YD (en relación con el periodo anterior, no con el posterior). Ante la pérdida de yacimientos en el YD se plantea la cuestión de: ¿a dónde se ha desplazado la población? Como no hay respuesta, la alternativa es proponer o un descenso poblacional, o cambios estratégicos en el poblamiento o pérdida tafonómica. Durante el 8.2, tomado como motor de cambios culturales de diversa naturaleza (transición del Neolítico precerámico al cerámico en el Próximo Oriente, difusión y diversificación agrícola en Europa, abandonos de sitios y regiones: González-Sampériz et al., 2009; Van der Plicht et al., 2011; Weninger et al., 2009; Berger and Guilaine, 2009) nuestro análisis no observa un cambio de tendencia (salvo el derivado de un valle en IntCal13).

\subsection{SCDPD y demografía}

Si las SCDPD reflejaran la dinámica del poblamiento teóricamente estaríamos en condiciones de calcular la tasa anual de crecimiento demográfico (Johnson y Brook, 2011; Riede, 2009; Shennan et al., 2013; Tallavaara et al., 2015; Collard et al., 2010; Downey et al., 2014; Hinz et al., 2012; Porčić et al., 2016) para compararla con la esperada capacidad reproductiva de sociedades no jerarquizadas. Sin embargo, un crecimiento de población no generará nuevos yacimientos hasta 
alcanzar el punto crítico según el cual el modo de vida no puede cubrir las necesidades y obliga a la fisión del grupo o a asumir otras formas socioeconómicas (Sahlins, 1987).

Sobre las dataciones calibradas reunidas en milenios aplicamos el cálculo de tasa demográfica: $\mathrm{T}$ = (Pa-Pp) /(a* Pp) (donte T = tasa; $\mathrm{Pa}=$ población actual; $\mathrm{Pp}=$ población de partida; $\mathrm{a}=$ amplitud cronológica).

El análisis es posible desde el inicio de la serie hasta los inicios del séptimo milenio, momento de pérdida de datos ante la reorganización social. El resultado es una tasa de 0,0012 $\pm 0,02 \%$, muy por debajo de la esperada para grupos de cazadores-recolectores

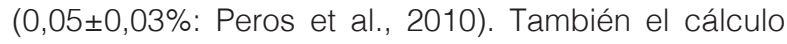
por milenios ofrece tasas inferiores a las debidas (material complementario 10). Extraemos dos conclusiones:

a) no es coherente utilizar las SCDPD como simulación de las dinámicas poblacionales;

b) el sesgo tafonómico es responsable principal de los desajustes, remitiendo a la hipótesis de partida: la invisibilidad de los yacimientos, sino su pérdida definitiva, condiciona nuestra visión del pasado.

\section{CONCLUSIONES}

El análisis de las dataciones radiocarbónicas no puede ser ajeno a la realidad arqueológica: tengamos en cuenta que el contexto arqueológico es el factor esencial en la comprensión y discusión de los resultados al determinar la composición, integridad y resolución de la base de datos. Sobre él actua un sesgo tafonómico: los repositorios reúnen de lo que se ha conservado lo datado. Y las políticas de investigación, los recursos técnicos, los económicos, y la disponibilidad de los arqueólogos seleccionan lo rescatado, analizado y publicado introduciendo un nuevo sesgo (Solheim y Persson, 2018).

Una de las dificultades de estos estudios tiene que ver con la calidad, escala y robustez de la base de datos. El marco será espacialmente macroregional, compilando información geográfica y culturalmente dispersa y afectada por situaciones prehistóricas heterogéneas: que los contextos arqueológicos estén datados es la excusa para tratarlos cronológicamente como un todo, cuando cada cual responderá a dinámicas propias que deben atenderse al interpretar los resultados. La problemática generada por los sesgos, los caracteres de las series radiocronológicas y las limitaciones el método son circunstancias que se repiten región por región: nuestras conclusiones para la península ibérica pueden, con los matices necesarios, ser válidas en otros contextos

La SCDPD de la península ibérica reúne, fundamentalmente, información: a) de determinadas regiones, y b) de yacimientos en refugios y de concheros. Es el reflejo de la situación ibérica que concentra los datos en la cornisa Cantábrica, cuenca del Ebro, Cataluña, Portugal y, según avanzamos en el del tiempo, Valencia, Meseta y Andalucía. Son muy relevantes los vacíos geográficos debidos, en gran medida, a razones tafonómicas: los yacimientos se concentran en entornos que disponen de cuevas y abrigos para presentarse más aislados en áreas carentes de estructura geológica adecuada para el desarrollo de refugios y muy alteradas por la remodelación geomorfológica holocénica.

Así el grueso de las dataciones se ha generado en depósitos con buenas condiciones de conservación y requisitos mínimos de visibilidad: las cuevas y los abrigos. Tras ellos los concheros, dadas sus particularidades, aportarán información significativa: en contra no es necesario reiterar las limitaciones que afectan a los poblados al aire libre, mayores cuanto menor es el grado de transformación de los espacios.

Sesgo de difícil control es el que tiene que ver con las estrategias de poblamiento y la movilidad de las sociedades. Por ejemplo: en el paso del Pleistoceno al Holoceno donde cambian los paisajes y las posibilidades; en el significado de los concheros, que formarían parte de un esquema de explotación económica complejo pero del que desconocemos las otras realidades poblacionales de los grupos que los crean; en la estabilización del Neolítico, con cambio en los patrones de poblamiento de tal manera que, sugerimos, las pérdidas en las frecuencias de las SCDPD parecen reflejar este hecho y tal vez no deben leerse en clave demográfica.

El sesgo de la investigación es otro factor determinante en los histogramas de frecuencias de probabilidad del C14: por ejemplo para el Mesolítico (Gallego, 2013) o en los inicios del Neolítico, periodo de especial investigación sobre el que se viene invirtiendo numerosos esfuerzos y recursos (Hernando, 1999) incluyendo la multiplicación del número de dataciones.

Finalmente debe reconocerse que la consideración de las dataciones como marcador de ocupación humana reduce el registro arqueológico disponible porque: a) son muchos los yacimientos carentes de referencias de cronología absoluta y b) no todos los yacimientos son susceptibles de ser datados por igual.

Este conjunto de observaciones debe tomarse como crítica positiva hacia un tema de moda en la disciplina prehistórica, pero necesario de reflexión para evitar automatismos analíticos.

\section{AGRADECIMIENTOS}

Agradecemos a T. A. Surovell (University of Wyoming) por su ayuda en la implementación de la fórmula del sesgo tafonómico y a I. Barbero y F. Vadillo por implicarse en las problemáticas estadísticas que les trasladamos. Buena parte del trabajo se ha discutido, lo que agradecemos vivamente, con los componentes del proyecto de investigación HAR2014-59042-P, del 
Ministerio de Ciencia y Tecnología del Gobierno de España del que el mismo forma parte. A. Soto desarrolla su trabajo al amparo de una beca de investigación postdoctoral del Gobierno Vasco. Destacamos asimismo el alto valor de las sugerencias de dos revisores anónimos a los que agradecemos su detenido trabajo.

\section{BIBLIOGRAFÍA}

Alday, A., Domingo, R., Sebastián, M., Soto, A., Aranbarri, J., González-Sampériz, P., Sampietro, M., Utrilla, P., Montes, L., Peña-Monné, J.L., 2018. The Silence of the Layers : Archaeological Site Visibility in the Pleistocene-Holocene Transition at the Ebro Basin. Quaternary Science Reviews 184, 85-106.

Alonso, C. (Ed)., 2017. Vida y Muerte En El Asentamiento Del Neolítico Antiguo de El Prado (Pancorbo, Burgos).Construyendo El Neolítico En La Península Ibérica. British Archaeological Reports 2876.

Aranda, G., Lozano, A., 2014. The Chronology of Megalithic Funerary Practices: A Bayesian Approach to Grave 11 At El Barranquete Necropolis (Almería, Spain). Journal of Archaeological Science 50, 369-382.

Arias, P., Cubas, M., Fano, M.A. Jordá Pardo, J.F., Salzmann, Ch., Teichner, F., Teira, L., 2015. Where Are the 'Asturian' Dwellings? An Integrated Survey Programme on the Mesolithic of Northern Spain. Antiquity 89, 783-799.

Attenbrow, V., Hiscock, P., 2015. Dates and Demography: Are Radiometric Dates a Robust Proxy for Long-Term Prehistoric Demographic Change? Archaeology in Oceania 50, 29-35.

Balsera, V., Díaz-del-Río, P., Gilman, A., Uriarte,A., y Vicent, J.M., 2015. Approaching the Demography of Late Prehistoric Iberia through Summed Calibrated Date Probability Distributions (7000-2000 Cal BC). Quaternary International 386, 208-11.

Balsera, V., Bernabeu J., Costa-Caramé, M., Díaz-del-Río, P., García Sanjuán, L., Pardo, S., 2015. The Radiocarbon Chronology of Southern Spain's Late Prehistory (5600-1000 Cal BC): A Comparative Review. Oxford Journal of Archaeology 34(2), 139-156.

Barandiarán, I., Cava, A., Alday, A., 2006. Ocupaciones de Altura e Interior Durante El Tardiglaciar: La Llanada Alavesa y Sus Estribaciones Montañosas. Zona Arqueológica 7(1), 535-550.

Barceló, J.A., 2008. La incertesa de les cronologies absolutes en arqueologia. Probabilitat i estadística. Cypsela 17, 23-33.

Bayliss, A., Woodman, P., 2009. A New Bayesian Chronology for Mesolithic Occupation at Mount Sandel, Northern Ireland. Proceedings of the Prehistoric Society 75, 101-23.

Berger, J.-F., Guilaine, J., 2009. The 8200 Cal BP Abrupt Environmental Change and the Neolithic Transition: A Mediterranean Perspective. Quaternary International 200, 31-49.

Bernabeu, J., García Puchol, O., Barton, M., McClure, S., Pardo, S., 2016. Radiocarbon Dates, Climatic Events, and Social Dynamics during the Early Neolithic in Mediterranean Iberia. Quaternary International 403, 201-10.

Bernabeu, J., García Puchol, O., Pardo, S. Barton, M.M., McClure, S., 2014. Socioecological Dynamics at the Time of Neolithic Transition in Iberia. Environmental Archaeology 19(3), 214-25.
Bicho, N., C. Umbelino, C. Detry, Pereira, T., 2010. The Emergence of Muge Mesolithic Shell Middens in Central Portugal and the $8200 \mathrm{Cal}$ Yr BP Cold Cvent. The Journal of Island and Coastal Archaeology 5, 86-104.

Blaauw, M., 2010. Methods and Code for 'Classical' Age-Modelling of Radiocarbon Sequences. Quaternary Geochronology $5(5), 512-518$

Blockley, S.P.E., Donahuea, R.E., Pollarda, A.M., 2000. Radiocarbon Calibration and Late Glacial Occupation in Northwest Europe. Antiquity 74, 112-19.

Bocquet-Appel, J.P., Naji, S., Vander, M., Kozloowski, J., 2012. Understanding the Rates of Expansion of the Farming System in Europe. Journal of Archaeological Science 39(2), 531-46.

Bourguignon, L., 2010. Le Diagnostic Des Sites Paléolithiques en Aquitaine. In: Le Diagnostic Des Sites Paléolithiques et Mésolithiques, 13-20. Les Cahiers de l'Inrap 3.

Buck, C.E., Kenworthy, J.B., Litton, C.D., Smith, A.F.M., 1991. Combining Archaeological and Radiocarbon Information: A Bayesian Approach to Calibration. Antiquity 65, 808-821.

Calcagnile, L., Quarta, G., Cattaneo, C., D’Elia, M., 2013. Determining $14 \mathrm{C}$ Content in Different Human Tissues: Implications for Application of $14 \mathrm{C}$ Bomb-Spike Dating in Forensic Medicine. Radiocarbon 55(2-3), 1845-1849.

Calvo, M., Ibáñez, J.J., González, J.E., 2009. Análisis Funcionales de Las Industrias Líticas Del Tardiglaciar En El Área Pirenaico-Cantábrica. In: XIV Col.Loqui Internacional D’ Arqueologia de Puigcerdá. Els Pirineus i Les Arees Circumdantes Durant El Tardiglacial, 239-281.

Carrión, Y., Kaal, J., López-Sáez, J.A., López-Merino, L., Martínez, A., 2010. Holocene Vegetation Changes in NW Iberia Revealed by Anthracological and Palynological Records from a Colluvial Soil. The Holocene 20(1), 1-14.

Collard, M., Edinborough, K, Shennan, S., Thomas, M.G., 2010. Radiocarbon Evidence Indicates That Migrants Introduced Farming to Britain. Journal of Archaeological Science 37, 866-870.

Contreras, D.A., Meadows, J., 2014. Summed Radiocarbon Calibrations as a Population Proxy: A Critical Evaluation Using a Realistic Simulation Approach. Journal of Archaeological Science 52, 591-608.

Cortés, M., Jiménez, F.J., Simón M.D., Gibaja, J.F., Carvalho, A.F., Martinez-Ruiz, F. Rodrigo, M., 2012. The Mesolithic-Neolithic Transition in Southern Iberia. Quaternary Research 77(2), 221-234.

Crombé, Ph., Robinson, E., 2014. 14C Dates as Demographic Proxies in Neolithisation Models of Northwestern Europe: A Critical Assessment Using Belgium and Northeast France as a Case-Study. Journal of Archaeological Science 52, 558-566.

Cubas, M., Altuna, J., Álvarez-Fernández, E., Armendáriz, A., Fano, M.A., López-Dóriga, I., Mariezkurrena, K., Tapia, J., Teira, L.C., Arias, P., 2016. Re-Evaluating the Neolithic: The Impact and the Consolidation of Farming Practices in the Cantabrian Region (Northern Spain). Journal of World Prehistory 29(1), 789-816.

Downey, S., Bocaege, E., Kerig, T., Edinborough, K. y Shennan, S., 2014. The Neolithic Demographic Transition in Europe: Correlation with Juvenility Index Supports Interpretation of the Summed Calibrated Radiocarbon Date Probability Distribution (SCDPD) as a Valid Demographic Proxy. PLoS ONE 9(8), e105730. 
Drake, B.L., Blanco-González, A., Lillios, K.T., 2016. Regional Demographic Dynamics in the Neolithic Transition in Iberia: Results from Summed Calibrated Date Analysis. Journal Archaeological Methods and Theory 24(3), 796-812.

Ducrocq, T., 2010. La Détection Des Sites Mésolithiques Dans Le Nord de La France. In Le Diagnostic Des Sites Paléolithiques et Mésolithiques, Les Cahiers de l'Inrap 3, 30-34.

Dupont, Ch., Marchand, G., 2016. Archéologie Des Chasseurs-Cueilleurs Maritimes de La Fonction Des Habitats à l'organisation de l'espace Littoral. Actes de La Séance de La Société Préhistorique Française de Rennes, 2014.

Evin, J., Fortin, P., Oberlin, C., 1995. Calibration et Modes de Représentation Des Datations Radiocarbones Concernant Le Néolithique de l'est et Du Sud-Est de La France. In: J.L. Voruz (ed.), Chronologies Néolithiques: De 6000 a 2000 Avant Notre Ėre Dans Le Bassin Rhodanien, 31-39. Documents du Département d'Anthropologie et d'Écologie de l'Université de Genève

Fano, M. A., 1998. El Hábitat Mesolítico En El Cantábrico Occidental. BAR International Series 732. Archaeopress, Oxford.

Fano, M.A., Cubas, M., Wood, R., 2015. The First Farmers in Cantabrian Spain: Contribution of Numerical Chronology to Understand an Historical Process. Quaternary International 364, 153-161.

Fernández López de Pablo, J., Gómez Puche, M., 2009. Climate change and population dynamics during the late Mesolithic and the Neolithic transition in Iberia. Documenta Praehistorica 36, 67-96.

Fort, J., 2015. Demic and Cultural Diffusion Propagated the Neolithic Transition across Different Regions of Europe. Journal of The Royal Society Interface 12 (106). doi: 10.1098/ rsif.2015.0166

French, J.C., Collins, C., 2015. Upper Palaeolithic Population Histories of Southwestern France: A Comparison of the Demographic Signatures of 14C Date Distributions and Archaeological Site Counts. Journal of Archaeological Science 55: 122-34.

Gallego, N., 2013. El Mesolítico en La Península Ibérica. Historia crítica de la investigación y estado actual del conocimiento. Tesis doctoral. Universidad Complutense de Madrid.

Gkiasta, M., Russell,T., Shennan, S., Steele, J., 2003. Neolithic Transition in Europe: The Radiocarbon Record Revisited. Antiquity $77:$ 45-62.

González-Sampériz, P., Utrilla, P., Mazo, C., Valero, B., Sopena, M.C. Morellón, M., Sebastián, M., Moreno, A., Martínez-Bea, M., 2009. Patterns of Human Occupation during the Early Holocene in the Central Ebro Basin (NE Spain) in Response to the 8.2 Ka Climatic Event. Quaternary Research 71(2), 121-32.

Guilderson, T.P., Reimer, P.J., Brown, T.A., 2005. The Boon and Bane of Radiocarbon Dating. Science 307, 362-364.

Hedges, R.E., Clement, J.G., Thomas, C.D., O'Connell, T.C., 2007. Collagen Turnover in the Adult Femoral Mid-Shaft: Modeled from Anthropogenic Radiocarbon Tracer Measurements. American Journal of Physical Anthropology 133(2), 808-16.

Hernando, A., 1999. Los Primeros Agricultores de La Península Ibérica. Síntesis.

Hinz, M., Feeser, I., Sjögren, K.G., Müller, J., 2012. Demography and the Intensity of Cultural Activities: An Evaluation of Funnel Beaker Societies (4200-2800 Cal BC). Journal of Archaeological Science 39(10), 3331-3340.
Housleya, R.A., Gamble, M-. Street, C.S., Pettitt, P., 1997. Radiocarbon Evidence for the Lateglacial Human Recolonisation of Northern Europe. Proceedings of the Prehistoric Society 63, 25-54.

Ibañez, J.J., González, J.E., 1998. The Production and Use of Lithic Tools and the End of the Upper Paleolithic Sites in the Basque Country. BAR International Seires 658.

Iriarte, M.J., 2006. El entorno vegetal del abrigo de Mendandia y su depósito arqueológico: análisis palinológico. In: Alday, A. (Dir.), El legado arqueológico de Mendandia: los modos de vida de los últimos cazadores en la Prehistoria de Treviño. 405418. Arqueología en Castilla y León. Memorias 15.

Iriarte, M.J., 2009. Vegetation Landscape and the Anthropization of the Environment in the Central Sector of the Northern Iberian Peninsula: Current Status. Quaternary International 200(1-2), 66-76.

Johnson, Ch., Brook, B.W., 2011. Reconstructing the Dynamics of Ancient Human Populations from Radiocarbon Dates: 10000 Years of Population Growth in Australia. Proceedings of the Royal Society of London B: Biological Sciences 278, 3748-3754.

Lillios, K.T., Blanco-González, A., Drake, B.E., López-Sáez, J.A., 2016. Mid-Late Holocene Climate, Demography, and Cultural Dynamics in Iberia: A Multi-Proxy Approach. Quaternary Science Reviews 135, 138-53.

López Sáez, J.A., López-Merino, L., Pérez Díaz, S., 2008. Crisis climáticas en la Prehistoria de la Península Ibérica: el Evento 8200 cal. BP como modelo. In: VII Congreso Ibérico de Arqueometría, 77-86.

Mangado, X., Bartrolí, R., Calvo, M., Fullola, J.M., Petit, M.A., 2005. Les Industries Lithiques de La Fin Du Paléolithique de La Grotte Du Parco (Alòs de Balaguer, Catalogne, Espagne). In: D'un Monde à l'autre. Les Systèmes Lithiques Pendant Le Tardiglaciaire Autour de La Méditerranée Nord-Occidentale, 11-24. Mémoire XL de La Société Préhistorique Française.

Martins, H., Oms, F.X., Pereira, L., Pike, A.W.G., Rowsell, K., Zilhão, J., 2015. Radiocarbon Dating the Beginning of the Neolithic in Iberia: New Results, New Problems. Journal of Mediterranean Archaeology 28(1), 105-131.

Michczynski, D.J., Michczynski, A., Pazdur, A., 2007. Frequency Distribution of Radiocarbon Dates as a Tool for Reconstructing Environmental Changes. Radiocarbon2 49(2), 799-806.

Montes, L., Alday, A., 2012. Enredados en la malla neolítica de la cuenca del río Ebro. Redes, Continuidades y Cambios. In Congrés Internacional Xarxes Al Neolític. Rubricatum 5, 51-60.

Morales, J.I., Oms, X., 2012. Las últimas evidencias mesolíticas del NE peninsuar y el vacío pre-Neolítico. In Congrés Internacional Xarxes Al Neolític. Rubricatum 5, 35-41.

Oberlin, C., 2003. Calibration Des Datations Radiocarbone: Point Sur La Période 6e-2e Millénaire Avant J.C. In: Gascó, J., Gutherz, X., Labriffe, P.A. de (Eds.), 35-42. Temps et Espaces Culturels Du 6e Au 2e Millénaire eEn France du Sud.

Olsen, J., Heinemeier, J., Hornstrup, K.M., Bennike, P., Thrane, H., 2013. 'Old Wood' Effect in Radiocarbon Dating of Prehistoric Cremated Bones? Journal of Archaeological Science 40(1), 30-34.

Pardo, P., Bernabeu, J. García,O., Barton, M., Bergin, S.M., 2015. The Origins of Agriculture in Iberia: A Computational Model, 117-131. Documenta Praehistorica 42. 
Peros, M.., Munoz, S.E. Gajewski, K., Viau, A., 2010. Prehistoric Demography of North America Inferred from Radiocarbon Data. Journal of Archaeological Science 37(3), 656-64.

Philibert, S., 1995. Temps et Spaces Sauveterriens: Contribution et Territoires Mésolithiques Pour l'analyse Tracéologique Des Industries Lithiques: L'exemple de Quatre Sites Saisonniers. In: L'Europe Des Derniers Chasseurs 145-55.

Plicht, J. Van der, Akkermans, P. Nieuwenhuyse, O., Kaneda, A., Russell, A., 2011. Tell Sabi Abyad, Syria: Radiocarbon Chronology, Cultural Change, and the 8.2 Ka Event. Radiocarbon 53, 229-43.

Porčić, M., Blagojević, T., Stefanović, S., Özdoğan, M., Brami, M., Heyd, V., Pinhasi, R., 2016. Demography of the Early Neolithic Population in Central Balkans: Population Dynamics Reconstruction Using Summed Radiocarbon Probability Distributions. PLOS ONE 11 (8): e0160832.

Rick, J.W., 1987. Dates as Data: An Examination of the Peruvian Preceramic Radiocarbon Record. American Antiquity 52(1), 55-73.

Riede, F., 2009. Climate and Demography in Early Prehistory: Using Calibrated $14 \mathrm{C}$ Dates as Population Proxies. Human Biology 81(2-3), 309-337.

Riede, F., Edinborough, K., 2012. Bayesian Radiocarbon Models for the Cultural Transition during the Allerod in Southern Scandinavia. Journal of Archaeological Science 39 (April 2016), 744-56.

Robinson, E., Van Strydonck, M., Gelorini, V., Crombé, Ph., 2013. Radiocarbon chronology and the correlation of Huntergatherer sociocultural change with abrupt palaeoclimate change: the middle Mesolithic in the Rhine-Meuse-Scheldt area of Northwest Europe. Journal of Archaeological Science 40(1), 755-63.

Rocha, L., 2003. Intervenções de Emergência Realizada Pela Extensão de Silves Do Instituto Português de Arqueologia: A. Praia Do Forte Novo (Quarteira, Loulé). Xelb 4, 161-74.

Rojo, M. A., Kunst, M., Garrido, R., García, I., Morán, G., 2008. Paisajes de La Memoria: Asentamientos del Neolítico Antiguo en el Valle de Ambrona (Soria, España). Universidad de Valladolid.

Rubinos Pérez, A., 2009. Límites de La Geocronología En El Estudio de Yacimientos de Época Histórica. Munibe (Antropologia-Arkeologia 6(0), 331-47.

Sahlins, M. 1987. Economía de la Edad de Piedra. Akal universitaria.

Shennan, S., Downey, S.S., Timpson, A., Edinborough, K., Colledge, S., Kerig, T., Manning, K., 2013. Regional Population Collapse Followed Initial Agriculture Booms in Mid-Holocene Europe. Nature Communications 531-46.

Solheim, S., Persson, P., 2018. Early and Mid-Holocene coastal settlement and demography in Southeastern Norway: comparing distribution of radiocarbon dates and Shoreline-Dated Sites, 8500-2000 cal. BCE. Journal of Archaeological Science: Reports 19 (June), 334-43.

Surovell, T.A., Brantingham, P.J., 2007. A Note on the Use of Temporal Frequency Distributions in Studies of Prehistoric Demography. Journal of Archaeological Science 34(11), 1868-77.

Surovell, T. A., Finley, J.B., Smith, G.M., Brantingham, P.J., Kelly, R., 2009. Correcting Temporal Frequency Distributions for Taphonomic Bias. Journal of Archaeological Science 36(8), 1715-24.
Tallavaara, M., Luoto, M., Korhonen, N., Järvinen, Seppä, H., 2015. Human Population Dynamics in Europe over the Last Glacial Maximum. Proceedings of the National Academy of Sciences of the United States of America 112(27), 8232-37.

Tarrus, J., 2008. La Draga (Banyoles, Catalonia), an Early Neolithic Lakeside Village in Mediterranean Europe. Catalan Historical Review 1, 17-33.

Terradas, X., González, J.E.. Rodriguez, A., Ibáñez, J.J., 2007. Los Territorios Prehistóricos Durante El Paso Al Holoceno En Los Dos Extremos Del Pirineo. In: Frontières Naturelles et Frontières Culturelles Dans Les Pyrènèes Préhistoriques, 161-82.

Timpson, A., Colledge, S., Crema, E., Edinborough, K., Kerig, T., Manning, K., Thomas, M.G., Shennan, S., 2014. Reconstructing Regional Population Fluctuations in the European Neolithic Using Radiocarbon Dates: A New Case-Study Using an Improved Method. Journal of Archaeological Science 52, 549-57.

Torfing, T., 2015. Neolithic Population and Summed Probability Distribution of 14C-Dates. Journal of Archaeological Science 63 (November), 193-198.

Ubelaker, D.H., Buchholz, B.A., Stewart, J.E.B., 2006. Analysis of Artificial Radiocarbon in Different Skeletal and Dental Tissue Types to Evaluate Date of Death. Journal of Forensic Sciences 51(3), 484-488

Utrilla, P., Montes, L. (Eds)., 2009. El Mesolítico Geométrico En La Península Ibérica. Monografías Arqueológicas 44. Universidad de Zaragoza.

Vaquero, M., García-Argüelles, P., 2009. Algunas Reflexiones Sobre La Ausencia de Mesolítico Geométrico En Cataluña. In: El Mesolítico Geométrico En La Península Ibérica. Monografías Arqueológicas 44, 191-204

Weninger, B., Jöris O., 2004. Glacial Radiocarbon Calibration. The CalPal Program. In: Higham, T., Bronk Ramsey, C., Owen, C. (eds.). Radiocarbon and Archaeology. Fourth International Symposium, 9-15. University School of Archaeology.

Weninger, B., Edinborough, K., Clare, L., Jöris, O., 2001. Concepts of Probability in Radiocarbon Analysis. Documenta Praehistorica 38(1), 1-20.

Weninger, B., Edinborough, K., Bradtmöller, M., Collard, M., Crombé, Ph., Danzeglocke, U., Holst, D., 2009. A Radiocarbon Database for the Mesolithic and Early Neolithic in Northwest Europe. In: Chronology and Evolution within the Mesolithic of North-West Europe, 143-76. Cambridge Scholars Publishing.

Wicks, K., Mithen, S., 2014. The Impact of the Abrupt 8.2ka Cold Event on the Mesolithic Population of Western Scotland: A Bayesian Chronological Analysis Using 'activity Events' as a Population Proxy. Journal of Archaeological Science 45, 240-69.

Williams, A.N., 2012. The Use of Summed Radiocarbon Probability Distributions in Archaeology: A Review of Methods. Journal of Archaeological Science 39(3), 578-89. doi: 10.1016/j. jas.2011.07.014

Williams, A.N., Ulm, S., 2016. Radiometric Dates Are a Robust Proxy for Long-Term Demographic Change: A Comment on Attenbrow and Hiscock (2015). Archaeology in Oceania. doi: 10.1002/arco.5095

Zahid, H.J., Robinson, E., Kelly, R., 2015. Agriculture, Population Growth, and Statistical Analysis of the Radiocarbon Record. Proceedings of the National Academy of Sciences 113(4), 931-35. 
